\title{
New Breakthroughs in Understanding the Role of Functional Interactions between the Neocortex and the Claustrum
}

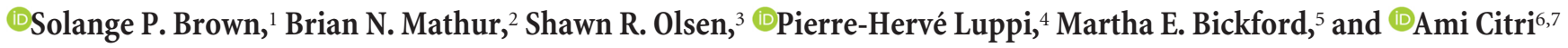 \\ ${ }^{1}$ Solomon H. Snyder Department of Neuroscience, Johns Hopkins University School of Medicine, Baltimore, Maryland 21205, ${ }^{2}$ Department of \\ Pharmacology, University of Maryland School of Medicine, Baltimore, Maryland 21201, ${ }^{3}$ Allen Institute for Brain Science, Seattle, Washington 98109 , \\ ${ }^{4}$ Institut National de la Santé et de la Recherche Médicale, U1028, Centre National de la Recherche Scientifique, Unité Mixte de Recherche 5292, University \\ Lyon 1, Lyon Neuroscience Research Center, Team “Physiopathologie des réseaux neuronaux responsables du cycle veille-sommeil,” Lyon 69372, France, \\ ${ }^{5}$ Department of Anatomical Sciences and Neurobiology, University of Louisville, Louisville, Kentucky 40202, 6 Edmond and Lily Safra Center for Brain \\ Sciences and Institute of Life Sciences, Hebrew University of Jerusalem, Edmond J. Safra Campus, Givat Ram, Jerusalem 91904, Israel, and 7Program in \\ Child and Brain Development, Canadian Institute for Advanced Research, MaRS Centre, West Tower, 661 University Avenue, Suite 505, Toronto, Ontario, \\ Canada, M5G 1M1
}

\begin{abstract}
Almost all areas of the neocortex are connected with the claustrum, a nucleus located between the neocortex and the striatum, yet the functions of corticoclaustral and claustrocortical connections remain largely obscure. As major efforts to model the neocortex are currently underway, it has become increasingly important to incorporate the corticoclaustral system into theories of cortical function. This Mini-Symposium was motivated by a series of recent studies which have sparked new hypotheses regarding the function of claustral circuits. Anatomical, ultrastructural, and functional studies indicate that the claustrum is most highly interconnected with prefrontal cortex, suggesting important roles in higher cognitive processing, and that the organization of the corticoclaustral system is distinct from the driver/modulator framework often used to describe the corticothalamic system. Recent findings supporting roles in detecting novel sensory stimuli, directing attention and setting behavioral states, were the subject of the Mini-Symposium at the 2017 Society for Neuroscience Annual Meeting.
\end{abstract}

Key words: attention; behavioral state; circuitry; claustrocortical; corticoclaustral; sensory modality

\section{Introduction}

The claustrum, a subcortical brain structure located between the neocortex and the striatum, is the most densely connected structure by volume in the human brain (Torgerson et al., 2015) and forms extensive reciprocal connections with the neocortex in mammals ranging from rodents to primates (Pearson et al., 1982; Fernández-Miranda et al., 2008; Zingg et al., 2014; Milardi et al., 2015; Torgerson et al., 2015; Atlan et al., 2017; Reser et al., 2017; Wang et al., 2017; White et al., 2017). The functions of the corticoclaustral system remain unclear in part because the claustrum's thin, elongated structure renders in vivo recordings during

\footnotetext{
Received Aug. 23, 2017; revised Sept. 29, 2017; accepted Sept. 29, 2017.

This work was supported by National Institute of Neurological Diseases R01NS085121 to S.P.B., National Institute on Alcohol Abuse and Alcoholism K22AA021414 and R01AA024845 to B.N.M., National Eye Institute R01EY016155 and R21EY021016 to M.E.B., Whitehall Foundation 2014-12-68 to B.N.M., Israel Science Foundation ISF 393/12 to A.C., Brain and Behavior Foundation NARSAD 18795 to A.C., Israel Anti-Drug Authority to A.C., Adelis Prize for Advances in Neuroscience to A.C., National Institute for Psychobiology in Israel NIPI 109-15-16 to A.C., Tiny Blue Dot Foundation to S.R.O., Centre National de la Recherche Scientifique, Université de Lyon and Université Lyon 1 to P.H.L., Johns Hopkins Discovery Fund to S.P.B., and Klingenstein-Simons Fellowship in the Neurosciences to S.P.B. We thank all those in our laboratories who have contributed to the studies described; and Juhyun Kim for help with the figure.

The authors declare no competing financial interests.

Correspondence should be addressed to Dr. Solange P. Brown, Solomon H. Snyder Department of Neuroscience, Johns Hopkins University School of Medicine, WBSB 906, 725 North Wolfe Street, Baltimore, MD 21205. E-mail: spbrown@jhmi.edu.

DOI:10.1523/JNEUROSCI.1837-17.2017

Copyright $\odot 2017$ the authors $\quad 0270-6474 / 17 / 3710877-05 \$ 15.00 / 0$
}

sensory and behavioral experiments particularly challenging. Likewise, the consequences of classic perturbations of claustral function (e.g., lesions, electrical stimulation) are difficult to interpret given the challenge of selectively targeting the claustrum without affecting surrounding structures. The bilateral nature of a number of the projections between the neocortex and the claustrum further complicates the interpretation of unilateral manipulations. Here, we review recent developments in systematically defining the claustrum and its cell types and elucidating its synaptic organization. We then compare corticoclaustral circuits with the driver/modulator framework used to describe corticothalamic interactions (Sherman and Guillery, 1998). Finally, we describe ongoing functional studies that have begun to test the claustrum's roles in signaling novel stimuli, directing attention, and setting vigilance states.

\section{Synaptic relationships within the corticoclaustral system}

The claustrum has traditionally been identified by its anatomical location and its patterns of connectivity and is thought to exist in all mammals (Mathur, 2014). Recent systematic studies of its long-range inputs and outputs have generated a more comprehensive definition of the claustrum in humans, nonhuman primates, and rodents (Fernández-Miranda et al., 2008; Zingg et al., 2014; Torgerson et al., 2015; Atlan et al., 2017; Reser et al., 2017; Wang et al., 2017; White et al., 2017). A molecular definition is also being developed (Mathur et al., 2009; Watson and Puelles, 
2017). The expression of several genes, including Gnb4, Gng2, Ntng2, and Nr4a2, is enriched in the claustrum in rodents and primates (Miyashita et al., 2005; Mathur et al., 2009; Wang et al., 2017). These molecular advances have suggested the existence of claustrum-like structures in birds and reptiles (Puelles et al., 2016), although the connectivity and function of these molecularly defined structures remain to be defined. These molecular studies, when combined with transgenic technology in the mouse, have begun to provide powerful tools for addressing the challenges to probing the function of claustral circuits in rodents. Transgenic mouse lines now enable relatively selective expression of Cre recombinase in claustral neurons to direct expression of a variety of genetically encoded constructs for monitoring and manipulating their activity.

\section{Patterns of long-range connectivity with the neocortex}

The claustrum is connected to nearly every cortical area. However, not all regions of the cortex are similarly connected to the claustrum (Fig. 1A). Recent comprehensive anatomical studies in rodents, monkeys, and humans have highlighted prominent reciprocal connections between the claustrum and frontal cortical areas (Pearson et al., 1982; Hoover and Vertes, 2007; Reser et al., 2014, 2017; Zingg et al., 2014; Torgerson et al., 2015; Atlan et al., 2017; Wang et al., 2017; White et al., 2017). Unlike connections with sensory and motor areas that involve relatively discrete zones within the claustrum, the connections with frontal areas in rodents are distributed throughout the claustrum (Atlan et al., 2017; White et al., 2017). Interestingly, cortical projections from frontal areas to the claustrum in the rodent are often bilateral, with in some cases, such as the anterior cingulate and whisker motor cortex, more prominent connections with the contralateral claustrum, whereas claustral projections to frontal areas are largely ipsilateral (Hoover and Vertes, 2007; Zingg et al., 2014; Wang et al., 2017; White et al., 2017). The function of these bilateral corticoclaustral projections remains unclear, although a role in the bilateral control of sensorimotor exploratory behaviors has been proposed (Smith and Alloway, 2014). Overall, these prominent connections between the claustrum and frontal cortical areas across mammalian species suggest an important role for the claustrum in higher cognitive functions.

In addition to the broad patterns of connectivity revealed by these systematic studies, more focused studies have demonstrated very specific patterns of connectivity between the claustrum and particular cortical regions. For example, in rats, motor areas associated with exploring the sensory world, such as whisker motor cortex and the frontal eye fields, largely project to contralateral claustrum and receive input from ipsilateral claustrum (Smith et al., 2012; Smith and Alloway, 2014). Interestingly, the related sensory areas, the barrel cortex and primary visual cortex, also receive input from ipsilateral claustrum but send only sparse projections back to the claustrum (Smith et al., 2012; Smith and Alloway, 2014; Zingg et al., 2014; Wang et al., 2017). Anatomical studies of corticoclaustral connectivity among different visual areas in the mouse have shown that the claustrum is more highly interconnected with ventral stream areas related to object recognition than with dorsal stream areas related to visuospatial recognition (Wang et al., 2012). These studies indicate that there are distinct patterns of connectivity with different cortical areas, and suggest that, rather than playing a diffuse modulatory role, these relationships underlie specialized roles in cortical processing.

\section{Local circuit organization and constraints on claustral function}

Recent studies on the local circuit organization of the corticoclaustral system in mice also place constraints on its possible function. The claustrum is largely composed of excitatory claustrocortical principal neurons, with GABAergic interneurons representing only $10 \%-15 \%$ of the neurons (Gómez-Urquijo et al., 2000). Paired recordings of neighboring claustrocortical cells measured a low probability of connection among these neurons (Kim et al., 2016), although it remains possible that defining subtypes of claustrocortical neurons or specific spatial relationships may reveal higher degrees of connectivity. Whether there are subregions within the claustrum or whether neuronal connections favor particular axes within the structure warrants further study.

Although several classes of inhibitory neurons in the claustrum have been revealed using immunohistochemical approaches, studies in many species, including humans, monkeys, cats, and rodents, have demonstrated that the claustrum is distinguished from surrounding structures by its prominent plexus of parvalbumin-positive (PV) fibers formed by local PV interneurons (Druga et al., 1993; Real et al., 2003; Hinova-Palova et al., 2007, 2014; Rahman and Baizer, 2007; Mathur et al., 2009). In mice, these fast-spiking PV interneurons are highly interconnected within the claustrum, both by chemical and electrical synapses (Fig. 1B) (Kim et al., 2016). PV interneurons are also highly interconnected with claustrocortical neurons, suggesting that this network of inhibitory neurons strongly modulates their activity (Kim et al., 2016). These local networks may synchronize the activity of claustrocortical projection neurons, influencing brain rhythms and coordinating the activity of different cortical brain regions (Bartos et al., 2007; Connors et al., 2010). However, depending on the behavioral state of the animal, such networks may 
also desynchronize claustral networks perhaps under the influence of the many neuromodulatory systems that are enriched in the claustrum (Connors et al., 2010; Baizer, 2014; Goll et al., 2015). Although the synaptic relationships and function of additional inhibitory cell types within the claustrum, such as somatostatin-positive neurons, remain to be elucidated, at least some of these additional classes of inhibitory neurons also form local connections with claustrocortical neurons.

\section{Corticoclaustral circuits do not fit the thalamic driver/modulator framework}

Because of the parallels between corticoclaustral neurons and the more well-studied corticothalamic cells, comparing corticoclaustral and corticothalamic connections may uncover clues to the function of corticoclaustral circuits. Both cell types project to structures reciprocally connected with the cortex. Similar to corticothalamic neurons, corticoclaustral neurons in cats and rodents have primarily been identified in layers 5 and 6 of the cortex (Olson and Graybiel, 1980; Sherk and LeVay, 1981; Katz, 1987; Grieve and Sillito, 1995; Smith and Alloway, 2010, 2014). Analogous to corticothalamic neurons (Bickford, 2015), corticoclaustral neurons form monosynaptic connections onto both claustrocortical projection neurons and inhibitory claustral interneurons (Juraniec et al., 1971; LeVay and Sherk, 1981; Hinova-Palova et al., 1988; Kim et al., 2016), and optogenetic activation of corticoclaustral axons elicits disynaptic inhibition in claustrocortical projection neurons (Kim et al., 2016).

A valuable framework for understanding thalamic circuits was proposed by Sherman and Guillery (1998) based on correlations between the structure and function of synaptic terminals within the dorsal thalamus. Most thalamic nuclei are innervated by very large terminals that typically provide $<10 \%$ of the synaptic inputs to thalamocortical relay cells and yet are the primary determinant of their receptive field properties. Thus, these inputs are considered "drivers" of thalamic activity. In contrast, most other thalamic terminals are much smaller, have more subtle effects on the receptive field properties of thalamocortical neurons, and are considered "modulators" of thalamic activity (for review, see Bickford, 2015).

Ultrastructural studies to determine whether corticoclaustral terminals exhibit features of either "drivers" or "modulators" revealed that the sizes of corticoclaustral terminals were not significantly different from the overall population of non-GABAergic terminals in the claustrum (Day-Brown et al., 2017). Comparison with thalamic terminals revealed that corticoclaustral terminals were intermediate in size, significantly larger than thalamic terminals classified as "modulators," but significantly smaller than thalamic terminals classified as "drivers." Therefore, the morphology of corticoclaustral terminals resembles neither a single prominent glutamatergic input that determines receptive field properties nor a modulatory input. Instead, the largest terminals in the claustrum are GABAergic, and these terminals contact dendrites and cell bodies that are significantly larger than the dendrites contacted by corticoclaustral or non-GABAergic terminals. These anatomical results in tree shrew indicate that the synaptic organization of the claustrum does not correspond with a driver/modulator framework. However, other key features of the driver/modulator framework, including the short-term synaptic plasticity and metabotropic glutamate receptor responses of corticoclaustral synapses, remain to be fully assessed (Sherman, 2016).

\section{Corticoclaustral circuits, novelty detection, and sensory processing}

Consistent with the electrophysiological studies of corticoclaustral inputs to local circuits within the mouse claustrum (Kim et al., 2016), ultrastructural studies in tree shrews suggest that the circuitry of the claustrum integrates convergent corticoclaustral inputs, gated by GABAergic circuits (Day-Brown et al., 2017). The intrinsic GABAergic connections identified electrophysiologically and anatomically may maintain inhibitory activity within the claustrum, which is overcome transiently by corticoclaustral connections to signal the appearance of salient sensory stimuli. The network organization of these GABAergic circuits fits well with the concept of the claustrum as a novelty detector to facilitate rapid shifts in attention (Mathur, 2014; Remedios et al., 2014; Goll et al., 2015). The novelty detector model also fits well with the large size of the tree shrew claustrum and the prominence of its connections with the visual cortex, as this is a fastmoving species that must rapidly detect salient stimuli to catch insects and avoid predators.

These results are also consistent with single-unit recordings of auditory and visual responses in the primate claustrum. Claustral neurons responded most strongly to the onset of sensory stimuli, suggesting that these cells were particularly sensitive to change (Remedios et al., 2010, 2014). Recent experiments in mice monitoring claustrocortical axonal activity to changing visual stimuli by combining selective expression of GCaMP6 in claustrocortical axons and mesoscale wide-field imaging of the cortex further suggest that the claustrum signals stimulus changes (Olsen, 2017). Interestingly, while claustrocortical input to visual cortical areas was engaged during this paradigm, the strongest responses measured were in higher-order regions of the cortex, including the anterior cingulate cortex, which is densely innervated by claustral projections.

Although the general features of the input-output connectivity of the claustrum have motivated the hypothesis that the claustrum is involved in binding information across sensory modalities (Pearson et al., 1982; Crick and Koch, 2005), recent studies in primates have found little evidence for multimodal responses in the claustrum during passive sensory tasks (Remedios et al., 2010, 2014). It remains important to determine whether the synaptic organization of the claustrum supports multimodal integration, and whether individual claustral neurons exhibit multimodal responses under specific behavioral conditions. It has also been proposed that the claustrum coordinates sensorimotor behaviors based on detailed studies of the relationships of claustral connections between sensory areas, such as somatosensory cortex and visual cortex, and motor areas, such as whisker motor cortex and the frontal eye fields, respectively, in rats (Smith and Alloway, 2010, 2014). Analyses of claustral function and perturbations of the corticoclaustral system during these behaviors in rodents and primates will be required to test its role in exploratory behaviors during active sensing. The relationships between these additional functions and the proposed role of corticoclaustral circuits in novelty detection also remain to be elucidated.

\section{Corticoclaustral circuits and attention}

The pattern of connectivity between the claustrum and sensory and frontal cortical regions in humans, nonhuman primates, and rodents has also suggested a role for corticoclaustral circuits in gating selective attention (Mathur, 2014; Goll et al., 2015). Recordings primarily in cats and primates show that claustral neurons respond to sensory stimuli and during voluntary movements (Olson and Graybiel, 1980; Sherk and LeVay, 1981; Shima et al., 1996; Remedios et al., 2010, 2014), form topographic maps 
for different sensory modalities and movements (Olson and Graybiel, 1980; Sherk and LeVay, 1981; Shima et al., 1996; Gattass et al., 2014), and can modulate the activity of cortical neurons (Ptito and Lassonde, 1981; Tsumoto and Suda, 1982). The claustrum may implement attentional strategies by selectively controlling the gain of cortical representations of sensory objects, thereby limiting the representation of irrelevant stimuli (Goll et al., 2015). More specifically, the claustrum may implement resilience to sensory distraction through divisive normalization, a canonical computation suggested to underlie the top-down allocation of selective attention and the separation of task-relevant from task-irrelevant stimuli (Treue and Martínez Trujillo, 1999; Carandini and Heeger, 2011). Thus, a deficit in claustral function would be expected to sensitize affected individuals to distractors (Tsuchiya and Koch, 2016). Experiments in rodents and primates modulating the activity of the claustrum to test whether it elicits a normalization of cortical sensory responses and diminishes the cortical representation of irrelevant sensory stimuli, thereby supporting a role in resilience to distraction, will be needed to directly test this hypothesis.

\section{Corticoclaustral circuits and vigilance states}

Several recent studies in rodents have implicated the claustrum in the regulation of rapid eye movement (REM) sleep. In most mammals, three vigilance states have been defined based on EEG, EMG, and EOG recordings: (1) waking (W), defined by a desynchronized EEG, phasic EMG activity, and ocular movements; (2) non-REM (also known as slow-wave) sleep defined by lowfrequency, high-amplitude delta oscillations on the EEG, low muscular activity on the EMG, and no ocular movement; and (3) REM (also known as paradoxical) sleep defined by a desynchronized EEG with complete disappearance of postural muscle tone and the occurrence of REMs and muscle twitches. The claustrum is one of two subcortical structures activated during REM sleep as shown by a systematic analysis of the expression of the immediate early gene c-Fos in rats (Renouard et al., 2015). In addition, anatomical experiments showed that the claustrum projects to the limited set of cortical areas also strongly activated during REM sleep, including anterior cingulate cortex and restrosplenial cortex, and suggest that the claustrum drives the activity of these cortical areas during REM. Similarly, recent experiments showed that glutamatergic neurons located in the mouse claustrum strongly project to the medial entorhinal cortex (Kitanishi and Matsuo, 2017), the only structure that projects to the ventral part of the dentate gyrus and strongly expressed Fos during REM sleep (Billwiller et al., 2017). These results suggest that the claustrum may directly activate the medial entorhinal cortices and indirectly activate the ventral dentate gyrus during REM sleep. Interestingly, the structures activated during REM sleep have all been implicated in spatial memory, suggesting that claustrocortical circuits may play a role in memory consolidation (Luppi et al., 2017). Claustral neurons may be activated during REM sleep by REM-active hypothalamic melanin-concentrating hormone neurons (Verret et al., 2003) that, in contrast to orexin neurons, innervate the claustrum in rats (Barbier et al., 2017). Future experiments in rodents and primates, including testing the effect on cortical activity during REM of inactivating the claustrum, are required to confirm these hypotheses.

In conclusion, substantial progress in elucidating the synaptic organization and function of the corticoclaustral system has generated several new hypotheses regarding the claustrum's effects on cortical function. Nonetheless, important questions remain regarding the cellular organization and function of the cortico- claustral system in different mammalian species. Whether there is a diversity of claustrocortical cell types with specific patterns of connectivity and what role the different classes of inhibitory neurons play remain unclear. Recent experiments on the synaptic organization of corticoclaustral projections and inhibitory circuits within the claustrum as well as on the responses of claustrocortical axons during sensory stimulation are consistent with a role as a novelty detector. Ongoing experiments also increasingly point to a role for corticoclaustral circuits in directing attention. A role in regulating the overall vigilance state of an animal is also increasingly implicated. The pattern of the claustrum's subcortical inputs and cortical outputs suggest that it functions as a relay station from the REM-sleep promoting system to activate the cortex during REM sleep. New developments, such as transgenic mouse lines with relatively selective expression in the claustrum combined with genetically encoded activity indicators and modulators, are enabling experiments in rodents that will directly test these hypotheses. Experiments in other animal species, including primates and humans, also remain necessary to probe the claustrum's contribution to cognitive functions in relevant behavioral paradigms across mammalian model systems.

\section{References}

Atlan G, Terem A, Peretz-Rivlin N, Groysman M, Citri A (2017) Mapping synaptic cortico-claustral connectivity in the mouse. J Comp Neurol 525: 1381-1402. CrossRef Medline

Baizer JS (2014) The neurochemical organization of the claustrum. In: The claustrum: structural, functional and clinical neuroscience (Smythies JR, Edelstein LR, Ramachandran VS, eds), pp 85-118. San Diego: Elsevier.

Barbier M, Houdayer C, Franchi G, Poncet F, Risold PY (2017) Melaninconcentrating hormone axons, but not orexin or tyrosine hydroxylase axons, innervate the claustrum in the rat: an immunohistochemical study. J Comp Neurol 525:1489-1498. CrossRef Medline

Bartos M, Vida I, Jonas P (2007) Synaptic mechanisms of synchronized gamma oscillations in inhibitory interneuron networks. Nat Rev Neurosci 8:45-56. CrossRef Medline

Bickford ME (2015) Thalamic circuit diversity: modulation of the driver/ modulator framework. Front Neural Circuits 9:86. CrossRef Medline

Billwiller F, Renouard L, Clement O, Fort P, Luppi PH (2017) Differential origin of the activation of dorsal and ventral dentate gyrus granule cells during paradoxical (REM) sleep in the rat. Brain Struct Funct 222:14951507. CrossRef Medline

Carandini M, Heeger DJ (2011) Normalization as a canonical neural computation. Nat Rev Neurosci 13:51-62. CrossRef Medline

Connors BW, Zolnik TA, Lee SC (2010) Enhanced functions of electrical junctions. Neuron 67:354-356. CrossRef Medline

Crick FC, Koch C (2005) What is the function of the claustrum? Philos Trans R Soc B Biol Sci 360:1271-1279. CrossRef Medline

Day-Brown JD, Slusarczyk AS, Zhou N, Quiggins R, Petry HM, Bickford ME (2017) Synaptic organization of striate cortex projections in the tree shrew: a comparison of the claustrum and dorsal thalamus. J Comp Neurol 525:1403-1420. CrossRef Medline

Druga R, Chen S, Bentivoglio M (1993) Parvalbumin and calbindin in the rat claustrum: an immunocytochemical study combined with retrograde tracing frontoparietal cortex. J Chem Neuroanat 6:399-406. CrossRef Medline

Fernández-Miranda JC, Rhoton AL Jr, Kakizawa Y, Choi C, Alvarez-Linera J (2008) The claustrum and its projection system in the human brain: a microsurgical and tractographic anatomical study. J Neurosurg 108:764774. CrossRef Medline

Gattass R, Soares JG, Desimone R, Ungerleider LG (2014) Connectional subdivision of the claustrum: two visuotopic subdivisions in the macaque. Front Syst Neurosci 8:63. CrossRef Medline

Goll Y, Atlan G, Citri A (2015) Attention: the claustrum. Trends Neurosci 38:486-495. CrossRef Medline

Gómez-Urquijo SM, Gutiérrez-Ibarluzea I, Bueno-López JL, Reblet C (2000) Percentage incidence of gamma-aminobutyric acid neurons in the claustrum of the rabbit and comparison with the cortex and putamen. Neurosci Lett 282:177-180. CrossRef Medline 
Grieve KL, Sillito AM (1995) Differential properties of cells in the feline primary visual-cortex providing the cortifugal feedback to the lateral geniculate-nucleus and visual claustrum. J Neurosci 15:4868-4874. Medline

Hinova-Palova DV, Paloff AM, Usunoff KG, Dimova RN, Yossifov TY, Ivanov DP (1988) Reciprocal connections between the claustrum and the auditory cortical fields in the cat: an experimental study using lightand electron microscopic anterograde degeneration methods, and the horseradish peroxidase retrograde axonal transport. J Hirnforsch 29:255278. Medline

Hinova-Palova DV, Edelstein LR, Paloff AM, Hristov S, Papantchev VG, Ovtscharoff WA (2007) Parvalbumin in the cat claustrum: ultrastructure, distribution and functional implications. Acta Histochem 109:6177. CrossRef Medline

Hinova-Palova DV, Edelstein L, Landzhov BV, Braak E, Malinova LG, Minkov M, Paloff A, Ovtscharoff W (2014) Parvalbumin-immunoreactive neurons in the human claustrum. Brain Struct Funct 219:1813-1830. CrossRef Medline

Hoover WB, Vertes RP (2007) Anatomical analysis of afferent projections to the medial prefrontal cortex in the rat. Brain Struct Funct 212:149-179. CrossRef Medline

Juraniec J, Narkiewica O, Wrzolkowa T (1971) Axon terminals in the claustrum of the cat: an electron microscope study. Brain Res 35:277-282. CrossRef Medline

Katz LC (1987) Local circuitry of identified projection neurons in cat visual cortex brain slices. J Neurosci 7:1223-1249. Medline

Kim J, Matney CJ, Roth RH, Brown SP (2016) Synaptic organization of the neuronal circuits of the claustrum. J Neurosci 36:773-784. CrossRef Medline

Kitanishi T, Matsuo N (2017) Organization of the claustrum-to-entorhinal cortical connection in mice. J Neurosci 37:269-280. CrossRef Medline

LeVay S, Sherk H (1981) The visual claustrum of the cat: I. Structure and connections. J Neurosci 1:956-980. Medline

Luppi PH, Billwiller F, Fort P (2017) Selective activation of a few limbic structures during paradoxical (REM) sleep by the claustrum and the supramammillary nucleus: evidence and function. Curr Opin Neurobiol 44:59-64. CrossRef Medline

Mathur BN (2014) The claustrum in review. Front Syst Neurosci 8:48. CrossRef Medline

Mathur BN, Caprioli RM, Deutch AY (2009) Proteomic analysis illuminates a novel structural definition of the claustrum and insula. Cereb Cortex 19:2372-2379. CrossRef Medline

Milardi D, Bramanti P, Milazzo C, Finocchio G, Arrigo A, Santoro G, Trimarchi F, Quartarone A, Anastasi G, Gaeta M (2015) Cortical and subcortical connections of the human claustrum revealed in vivo by constrained spherical deconvolution tractography. Cereb Cortex 25:406-414. CrossRef Medline

Miyashita T, Nishimura-Akiyoshi S, Itohara S, Rockland KS (2005) Strong expression of NETRIN-G2 in the monkey claustrum. Neuroscience 136: 487-496. CrossRef Medline

Olsen SR (2017) Claustral-cortical communication in a visual change detection task (Program 18002). 2017 Neuroscience Meeting Planner. Washington, DC: Society for Neuroscience.

Olson CR, Graybiel AM (1980) Sensory maps in the claustrum of the cat. Nature 288:479-481. CrossRef Medline

Pearson RC, Brodal P, Gatter KC, Powell TP (1982) The organization of the connections between the cortex and the claustrum in the monkey. Brain Res 234:435-441. CrossRef Medline

Ptito M, Lassonde MC (1981) Effects of claustral stimulation on the properties of visual cortex neurons in the cat. Exp Neurol 73:315-320. CrossRef Medline

Puelles L, Ayad A, Alonso A, Sandoval JE, Martínez-de-la-Torre M, Medina L, Ferran JL (2016) Selective early expression of the orphan nuclear receptor Nr4a2 identifies the claustrum homologue in the avian mesopallium: impact on sauropsidian/mammalian pallium comparisons. J Comp Neurol 524:665-703. CrossRef Medline

Rahman FE, Baizer JS (2007) Neurochemically defined cell types in the claustrum of the cat. Brain Res 1159:94-111. CrossRef Medline

Real MA, Davíla JC, Guirado S (2003) Expression of calcium-binding proteins in the mouse claustrum. J Chem Neuroanat 25:151-160. CrossRef Medline
Remedios R, Logothetis NK, Kayser C (2010) Unimodal responses prevail within the multisensory claustrum. J Neurosci 30:12902-12907. CrossRef Medline

Remedios R, Logothetis NK, Kayser C (2014) A role of the claustrum in auditory scene analysis by reflecting sensory change. Front Syst Neurosci 8:44. CrossRef Medline

Renouard L, Billwiller F, Ogawa K, Clement O, Camargo N, Abdelkarim M, Gay N, Scote-Blachon C, Toure R, Libourel PA, Ravassard P, Salvert D, Peyron C, Claustrat B, Leger L, Salin P, Malleret G, Fort P, Luppi PH (2015) The supramammillary nucleus and the claustrum activate the cortex during REM sleep. Sci Adv 1:e1400177. CrossRef Medline

Reser DH, Richardson KE, Montibeller MO, Zhao S, Chan JM, Soares JG, Chaplin TA, Gattass R, Rosa MG (2014) Claustrum projections to prefrontal cortex in the capuchin monkey (Cebus apella). Front Syst Neurosci 8:123. CrossRef Medline

Reser DH, Majka P, Snell S, Chan JM, Watkins K, Worthy K, Quiroga MD, Rosa MG (2017) Topography of claustrum and insula projections to medial prefrontal and anterior cingulate cortices of the common marmoset (Callithrix jacchus). J Comp Neurol 525:1421-1441. CrossRef Medline

Sherk H, LeVay S (1981) Visual claustrum: topography and receptive field properties in the cat. Science 212:87-89. CrossRef Medline

Sherman SM (2016) Thalamus plays a central role in ongoing cortical functioning. Nat Neurosci 19:533-541. CrossRef Medline

Sherman SM, Guillery RW (1998) On the actions that one nerve cell can have on another: distinguishing "drivers" from "modulators." Proc Natl Acad Sci U S A 95:7121-7126.

Shima K, Hoshi E, Tanji J (1996) Neuronal activity in the claustrum of the monkey during performance of multiple movements. J Neurophysiol 76: 2115-2119. Medline

Smith JB, Alloway KD (2010) Functional specificity of claustrum connections in the rat: interhemispheric communication between specific parts of motor cortex. J Neurosci 30:16832-16844. CrossRef Medline

Smith JB, Alloway KD (2014) Interhemispheric claustral circuits coordinate sensory and motor cortical areas that regulate exploratory behaviors. Front Syst Neurosci 8:93. CrossRef Medline

Smith JB, Radhakrishnan H, Alloway KD (2012) Rat claustrum coordinates but does not integrate somatosensory and motor cortical information. J Neurosci 32:8583-8588. CrossRef Medline

Torgerson CM, Irimia A, Goh SY, Van Horn JD (2015) The DTI connectivity of the human claustrum. Hum Brain Mapp 36:827-838. CrossRef Medline

Treue S, Martínez Trujillo JC (1999) Feature-based attention influences motion processing gain in macaque visual cortex. Nature 399:575-579. CrossRef Medline

Tsuchiya N, Koch C (2016) The relationship between consciousness and top-down attention. In: The neurology of consciousness: cognitive neuroscience and neuropathology (Laureys S, Gosseries O, Tononi G, eds), pp 71-91. San Diego: Academic.

Tsumoto T, Suda K (1982) Effects of stimulation of the dorsocaudal claustrum on activities of striate cortex neurons in the cat. Brain Res 240:345349. CrossRef Medline

Verret L, Goutagny R, Fort P, Cagnon L, Salvert D, Léger L, Boissard R, Salin P, Peyron C, Luppi PH (2003) A role of melanin-concentrating hormone producing neurons in the central regulation of paradoxical sleep. BMC Neurosci 4:19. CrossRef Medline

Wang Q, Sporns O, Burkhalter A (2012) Network analysis of corticocortical connections reveals ventral and dorsal processing streams in mouse visual cortex. J Neurosci 32:4386-4399. CrossRef Medline

Wang Q, Ng L, Harris JA, Feng D, Li Y, Royall JJ, Oh SW, Bernard A, Sunkin SM, Koch C, Zeng H (2017) Organization of the connections between claustrum and cortex in the mouse. J Comp Neurol 525:1317-1346. CrossRef Medline

Watson C, Puelles L (2017) Developmental gene expression in the mouse clarifies the organization of the claustrum and related endopiriform nuclei. J Comp Neurol 525:1499-1508. CrossRef Medline

White MG, Cody PA, Bubser M, Wang HD, Deutch AY, Mathur BN (2017) Cortical hierarchy governs rat claustrocortical circuit organization. J Comp Neurol 525:1347-1362. CrossRef Medline

Zingg B, Hintiryan H, Gou L, Song MY, Bay M, Bienkowski MS, Foster NN, Yamashita S, Bowman I, Toga AW, Dong HW (2014) Neural networks of the mouse neocortex. Cell 156:1096-1111. CrossRef Medline 